\title{
REVIEW OF VARIED PERCEPTIONS OF SEXUAL HARASSMENT AND ITS IMPLICATION IN THE WORKPLACE
}

\author{
Martina A. Pojwan ${ }^{1}$ and Mohammed Osoki ${ }^{2}$ \\ ${ }^{1}$ Department of Social Development, Isa Mustapha Agwai 1 Polytechnic, Lafia. Nasarawa \\ State. Email: satzen29@yahoo.com (08036641565) \\ ${ }^{2}$ Department of Social Development, Isa Mustapha Agwai 1 Polytechnic, Lafia. Nasarawa \\ State. Email: mohammedosoki@gmail.com (08036365203)
}

Cite this article:

Pojwan M.A., Osoki M. (2021), Review of Varied Perceptions of Sexual Harassment and Its Implication in the Workplace. African Journal of Social Sciences and Humanities Research 4(4), 140-148. DOI: 10.52589/AJSSHR4DRPCOEF.

\section{Manuscript History}

Received: 21 Oct 2021

Accepted: 9 Nov 2021

Published: 27 Nov 2021

Copyright $\odot 2020$ The Author(s). This is an Open Access article distributed under the terms of Creative Commons AttributionNonCommercial-NoDerivatives 4.0 International (CC BY-NC-ND 4.0), which permits anyone to share, use, reproduce and redistribute in any medium, provided the original author and source are credited.
ABSTRACT: This paper reviewed the perception of sexual harassment of employees in the work environment. It examined the nature of sexual harassment, its causes and its implication on the Nigerian worker. A review of related works of literature on the topic under study was done and the paper shows that workplace sexual harassment is a social problem that depends on gender, context and perceived ideology. It also buttressed that apart from the social and political factors that make women more vulnerable to sexual harassment than men, cultural factors play a prominent role. The researchers recommend among other things that psychological dynamics underlying the perception of sexual harassment should be examined critically by researchers, in order to be able to identify harassment that is just a figment of the perceiver's imagination and actual sexual harassment. Also, victims of sexual harassment should be protected by stringent legislation to deter any harasser in the workplace, and there should be a forum for victims to report and voice out their grievances.

KEYWORDS: Sexual Harassment, Perception, Work Environment. 


\section{INTRODUCTION}

The Nigerian society is undergoing rapid social transition, making more and more women enter the work environment than before. The bulk of discussion on diverse inequalities in the work place, including low pay, lower job status, restriction from certain jobs as well as confinement to sex-type jobs, have been done severally. Unfortunately, the issue of sexual harassment at work seems to attract less attention (Yusuf, 2008) leading to stress vis-a-vis gender in a patriarchal society such as the Nigerian work environment. Sexual harassment is degrading and it is a massive problem in Nigerian institutions and workplaces; it is now a public social problem which depends on the gender, context and perceived ideology. This is because victims' perceptions and experiences are often poorly understood in low and middle income societies like Nigeria (Worke \& Debelew, 2021). Studies have buttressed that female workers in most work environments are particularly affected by this menace due to sociocultural undertones and gender stereotypical perception of women. Everyday, thousands of women (and men, a few times) are predominantly harassed by their employees, colleagues or teachers.

The past decade has witnessed the pervasiveness and the high cost of sexual harassment, which is a manifestation of sex-based discrimination and it has become a national and even a global issue of concern in many work environments (International Labour Organization, ILO, 2012). Sexual harassment is a widespread phenomenon that undermines equality at work and it can have a negative impact on victims, salaries, career progression, working conditions and can even drive some individuals out of the world of work completely (ILO, 2012) .

There has been a serious debate on what sexual harassment is. While others see it as just misinterpretation of intention and friendliness and/or clumsy and insensitive expression of attraction, others are of the opinion that it is a deliberate and repeated sexual behavior that is unwelcome to its recipient, as well as other sex related behaviors that are hostile, offensive or degrading (Fitzgerald, 1993).

Even though sexual harassment has been investigated in developed countries, empirical research has not led to firm conclusions about its antecedents and consequences, both at personal and organizational levels. This is because one major problem of any sexual harassment on the job is its perceptual nature (Topa, Morales \& Depolo, 2008) and the age/status of the victim. Other investigators have also concluded that women have a broader definition of sexual harassment compared to their male counterparts. Women term negative attitudes from men, like teasing, looks, gestures, unnecessary physical contact and remarks, to be sexual harassment. They view such as more serious problems than men. This present study is undertaken to explore the varied perception of sexual harassment in the work environment and how sexually harassed persons can cope with such issues; related theory will be examined and conclusion/recommendations will be made.

\section{Concept of Sexual Harassment}

Sexual harassment is defined by law to include request for sexual favors, sexual advances either explicitly or implicitly, and a condition affecting academic or employment decisions. This means it could be a physical, verbal and/or non-verbal behaviour towards the victim. ILO (2012) defines sexual harassment as a sex-based behaviour that is unwelcome and offensive to its victim. Sexual harassment in organizations take two forms: for job benefits such as rise in pay, promotion or even continued employment; or because of hostile work environment in 
which the conduct creates conditions that are intimidating/humiliating to the victim (ILO, 2012). This behavior, when it is sufficiently severe or pervasive and creates an intimidating, hostile and repugnant environment, and persists despite objection by the person which it is directed to, is termed sexual harassment. Sexual harassment is an unwelcome sexual advance, unwelcome request for sexual favours or other unwelcome conducts of a sexual nature which makes a person feel offended, humiliated and/or intimidated, and a reasonable person would anticipate an adverse reaction in such circumstance. Furthermore, Ayub and Adegboyega (2020) assert that the act of sexual harassment within the workplace is usually either explicit or implicit, where a potential victim is conditioned to give in, in order to secure favours such as employments, promotion and any other opportunity. Such misconducts have great effects of substantially interfering with the individual's organizational or professional performance and creating an unhealthy work environment (Ladebo, 2003). The above assertion has been supported by Chamie (2017) in his findings on sexual harassment; it revealed that not less than $75 \%$ of the world's 2.7 billion women aged 18 years and above have experienced sexual harassment.

The Sex Discrimination Act (1984) defines the nature and circumstances in which sexual harassment is as unlawful. It is also unlawful for a person to be victimized for making - or proposing to make - a complaint of sexual harassment to the Human Rights and Equal Opportunity Commission.

A court judgment in India in 1997 led to a definition of sexual harassment that is more encompassing; it was defined as any unwelcome sexually determined behavior such as physical contact, demand or request for sexual favors, sexually colored remarks, showing pornography or any other physical, verbal or non-verbal act of sexual tendency. If any person could identify that he or she was exposed to the above, it was considered as complete knowledge and definition of sexual harassment. Fitzgerald and Gelfand (1995) emphasize that the dimension of sexual harassment can be viewed as gender harassment, unwanted attention and sexual coercion. To them, for any act to be termed sexual harassment, there must be a serious effect on the victim's psychological well-being before the individual can talk about being harassed sexually.

Definitions and research on this subject matter make it clear that sexual harassment is judged based on the perception, conduct and its effect on the harassed. In essence, perception of harassment may be dependent on some attributes of the victims. The self-esteem of an individual may greatly influence the behaviors and actions that such an individual will perceive as sexual harassment, meaning it is socially constructed and varies with the characteristics of the individual. The influence of self-esteem on perception of sexual harassment can be seen in the pattern of reports of harassment. Female professionals believed to have high self-esteem are likely to report subtle behaviors as harassment than those women in the secretariat-clerical positions believed to have low self-esteem (Mclntyre \& Beruck, 1982). So, sexual harassment may not necessary be seen as causing 'psychological injury' to the harassed but that the environment is reasonably being perceived as sexually hostile and abusive.

Sexual harassment therefore is a sexual attack or a situation of being disturbed and worried sexually by another person. It is generally a social problem which normally generates a lot of controversies basically because, as seen above, it is a relative concept where what one calls harassment might not be so to another. Although research into this phenomenon is not recent, 
the constant prevalence and dimension of its occurrences are alarming. The factors that influence a worker's perception of harassment will now be examined.

\section{Factors Influencing Perception of Harassment}

There are numerous factors that influence how the harassed perceive sexual harassment. They include the personality of the individual, self-esteem, background, culture, age, education and marital status.

Personal vulnerability function and the self-esteem of the individual are major determinants of perceptual tendency of being harassed. An individual who sees himself/herself as capable, independent and up to the task is more likely to perceive subtle behaviors as sexual harassment, but a dependent and vulnerable person is more tolerating and vulnerable to behaviors that can be described as sexual harassment, all because of their low self-esteem. This can be explained by the notion that sexual harassment has cut across all strata of the society, leading to dynamics of position and dominion as well as sexuality. The status of the recipient may influence his/her perception of harassment which may be in terms of position, power, marriage or education. For example, just as women with lower positions hardly perceive what should be sexual harassment as such, especially when cooperation and acceptance of the behavior is perceived as rewarding, such as better grades in an examination, promotion, pay rise and other reinforcement, people with power, position and high status are likely to perceive subtle behaviors as harassment. The attribution of the individual is a major determinant also. Attribution here means how a person sees and explains events that happens to him/her, whether it is the result of his/her own ability or inability, or whether it is as a result of the environmental/situational factors. Whichever side the individual falls into determines his/her perception of harassment. For instance, Riger (1991) observed that some women consider sexual harassment to be normative; in other words, it is a normal way of life, like online behavior cannot be challenged. By implication, people in this category will not perceive subtle behaviors and even some suggestive gestures as sexual harassment.

Males are also affected by normative beliefs in that they are expected to be flattered and happy if a female makes sexual advances at them. Rejection would be considered as an insult to womanhood. Ultimately, this belief affects males' perception and interpretations of sexual harassment, so they tend not to see most subtle behaviors as harassing and as such, they have a generally low perception of sexual harassment compared to females. Sex has a great influence on sexual harassment, making females see subtle behaviors as sexual harassment than males. As a matter of fact, males expect females to appreciate and enjoy teasing, likes and some other form of sexual attention, whereas females are likely to consider all those as insulting. Differences in the perception of males and females could be as a result of several factors. One is the traditional dominant role of men and the passive role of women in the society. Men are deemed to have their way where women are concerned. Women are seen as objects of sex that can be used any time. In some cultures, women are not to be heard; they are servile to the men and this has differential implications on what they perceive as sexual harassment because men see sexual advances and gestures as their right; they perceive harassment less, but women who are coming out of their traditional passive roles perceive the behavior as uncalled for, indecent and a violation of their right. This results in them having a higher perception of sexual harassment. 
More so, educational status can also influence what an individual perceives as sexual harassment. A well-educated individual will be quick to decode and interpret any behavior that has the appearance of sexual harassment and so will perceive more behaviors and gestures as harassing, compared to uneducated individuals. For example, a university graduate may perceive subtle gestures as sexual harassment while a secondary school student may see the same gestures as a show of affection or a normal way of life.

Looking at physical attractiveness, it is generally accepted that tall men with broad chests, muscular upper bodies and smaller waists are considered more dominant and more attractive (Horvath, 1979, 1981; Kennick, 1987; Single, 1995). So if these men demonstrate any subtle sexual behavior or gesture, it will be okay with many women or girls, while those men that lack such attributes will be accused of harassing such women if same behavior is displayed. Likewise, women with likable attributes are not likely to be accused by men when they display such gestures that could be termed as sexual harassment unlike when they are displayed by those women or girls with unlikable attributes.

Age also has a significant positive influence on the perception of sexual harassment. Younger persons have lower perception of sexual harassment than older individuals, especially when the harassed is someone probably in need of a suitor. Marital status, as stated earlier, has an implication on sexual harassment. Singles may see harassment as part of life and fun that makes life go on. Omonijo, Uche, Nwadiafor, and Rotimi (2013) undertook a study on the prevalence of sexual harassment and it was found that female students experienced sexual harassment more in comparism with men.

\section{EMPIRICAL REVIEW}

An explorative qualitative study was conducted by Worke, Koricha and Debelew (2021). The findings of the research show that most participants perceived sexual harassment to include pressuring, threatening, touching and adopting sexual advances through verbal, physical, and nonverbal types. The perceived risks factors were related to the organizations, the employees and the victims with the consequences being work, health, financial and or family related.

ILO (2020) observed in a survey by Australian Equal Opportunity Commission in 2004 that $18 \%$ of the participants aged between 18 and 64 years said they had experienced sexual harassment in the workplace, $62 \%$ of them were physically harassed and less than $37 \%$ were likely to report the abuse.

A study conducted on Experience of Sexual Harassment at Work by Female Employees in a Nigerian Work Environment (Yusuf, 2010) revealed that majority of the respondents had experienced some kinds of sexual harassment, usually from their male superiors. The study also shows that sociocultural factors dictated their varying responses, which include concealment of such acts by the victims due to fear of shame, discrimination and ignorance of channels of legal redress. It was recommended therefore that enlightenment campaigns by stakeholders at various levels should always be undertaken to enlighten victims on their rights to legal redress whenever they are sexually harassed. 


\section{Implication of Being Sexually Harassed}

Being sexually harassed can impact on the psychological health causing physiological reactions; it can also impact on the physical well-being and vocational development. Psychological, physiological and physical reactions may include sexual problems, panic reactions, gastrointestinal distress, lethargy, depression, irritability, and insecurity, among others (CVA \& VPV, 2020). The effects and consequences of sexual harassment are such that they can leave a permanent scar on the psyche of the victims. It introduces dissonance into their cognition and can greatly impair their functions and interaction throughout their lifetime. Sexual harassment is degrading, frightening, and can result in profound job related psychological and health consequences (Fitzgerald, 1993). It can lead to lowered self-esteem, decreased feelings of competence and confidence, and increased feelings of anger, frustration, depression and anxiety. These mentioned consequences have direct implication on not just the mental health of the worker but also on the efficiency, performance and finally productivity or output of the sexually harassed victim. Anierobi, Etodike, Nwogbo, Okeke and Nwikpo (2021) posit that sexual harassment against women has many consequences including negative effects on the woman as an individual regarding her work productivity.

\section{THEORETICAL FRAMEWORK}

There are several theories and perspectives that provide explanation to the issues of sexual harassment. Some them are patriarchal capitalism, Marxist theory and feminist perspective. Patriarchal capitalism theory views the position of women in the labour market as a product of both the economic relations of capitalism and patriarchal gender relations. Hartmann (1981) posit that segregation by sex and women's sexual exploitation can be explained by employing the way patriarchy and capitalism work to exploit the woman. In the social system, male dominant power is based on their control of female labour in both the family and the labour market. This leads to sexual segregation in the labour market which has served to secure male dominance. This theory then regards sexual harassment of female workers by their male counterparts as a reflection of the male-dominated society and economic system. The import of this theory would be that as long as a society is organized along the patriarchal system, it tends to condone acts and practices that are discriminatory towards the female gender.

Marxists conception of gender relations is largely in terms of exploitation and oppression. Sexual oppression is used to denote the many ways in which women are socially and sexually subordinated because of their gender (Pollert, 1985). This situation is believed to be mediated and reproduced through gender relations between men and women. The sexual division of labour brought by the male dominated sexist ideology further strengthens the pattern of women exploitation. Although capitalism is viewed as "progressive" for women in that it throws them into wage labour, it is also "progressive" in a contradictory way since it also intensifies their oppression by creating the double burden of economic exploitation and domestic labour. Again, in the same way the theory of patriarchal capitalism shows the correlation between economic relations and women exploitation at the workplace, Marxist theory of gender relations similarly reflects on the exploitation of women which could manifest as sexual harassment. 
Adkins, as cited in Yusuf (2008), advances the sexuality theory of gender that explains the differential experiences of women and men in the labour market based on their sex. The theory acknowledges the centrality of sexuality in the labour market as a factor in the work experience of female workers. She bases her theory on the tourism industry, which led her to explore how relations of sexuality are central in constructing women and men as different types of workers. She argues that feminists have concentrated on how women's labour is controlled through their exclusion from jobs and wages or via segregation within jobs. She further asserts that the labour market is more gendered than the dual systems approach suggests. The labour market is in this regard not only a site of inequality but also where meanings about gender and sexuality are constructed. It is said that jobs in hotels were gender segregated with positions such as receptionist and housekeeper being performed by women, and porters and kitchen assistants by men. She emphasizes that the control of women labour in tourism involves sexuality and the compulsion for women to be what is referred to as "sexual workers". Women and men may do the same job but they are different kinds of workers, as women's work involves "sexual servicing". The Marxist theory of sexual exploitation is adopted to guide this paper. This is because, principally, sexual harassment seems to be a by-product of the capitalist relations of production with its attendant exploitation of various categories of the workers, in this case, female workers.

\section{CONCLUSION}

What connotes sexual harassment is perceived differently by the harassed and the society. Factors such as culture, gender, marital status, position, power, physical attractiveness, age, personality differences, education and exposure have implications on our interpretation of what sexual harassment is, whether at work or at school or even market and other public places. For instance, men and women differ in their awareness as to what constitutes sexual harassment. Sexual harassment can impact on psychological health causing physiological reactions; it can also impact on physical well-being and vocational development. Psychological, physiological and physical reactions may include sexual problems, panic reactions, gastrointestinal distress, lethargy, depression, irritability, and insecurity, among others.

Sexual harassment is still widespread in the work space, and thorough societal change is needed. So, to address this gender-based violence, it is necessary to tackle its underlying causes and various risk factors. These include gender stereotypes, multiple and intersecting forms of discrimination, and unequal gender-based power relations (ILO, 2020).

\section{RECOMMENDATIONS}

After a thorough review of various perceptions of sexual harassment, the researchers recommend the following:

1. Psychological dynamics underlying the perception of sexual harassment should be examined more critically by researchers, in order to be able to identify harassment that is just a figment of the perceiver's imagination. 
2. Organizations should be encouraged to include sexual safeguard and resolution procedure in their policies, in order to prevent harassment or minimize such and insulate employees and prospective employees against the menace of sexual harassment.

3. Government and all stakeholders, whether in private or public sectors, should educate all and sundry on the definitions and psychological dangers of sexual harassment, and punitive measures should be recommended for defaulters.

4. Enlightenment campaigns and awareness to all workers on their rights to legal redress, if they are sexually harassed at work, should always be done by Non-governmental Organizations (NGOs) and other stakeholders to protect the rights of workers, particularly female employees. Also, the active involvement of trade unions in efforts meant to reduce the incidence of sexual harassment at the workplace will go a long way to tackle the menace of sexual harassment in the Nigerian work environment.

5. Victims of sexual harassment should be protected by stringent legislation to deter any harasser in the workplace, and there should be a forum for victims to report and voice out their complaints of such ill treatment without discrimination in the workplace, for healthier work space.

\section{REFERENCES}

Abbey,A.and Melby,C.(1986). The effect of non-verbal cues on gender difference in the perception of sexual intent. Sex Roles 15,283-298.

Abby, A. (1982), Sex differences in attribution for friendly behavior. Do males mis-perceive females friendliness? Journal of personality and social psychology, 42,830-838.

Adkins (1995). Gendered Work: Sexuality, Family and the Labour Market. Open University Press.

Anierobi, E. I., Etodike, C.E., Nwogbo,V.N., Okeke,N. U., \&Nwkpo, M.N.(2021). Evaluating sexual harassment against female workers in higher in Anambra State. International Journal of Academic Research in business and social sciences.11(2) 265278.

Ayub, A. O., and Adegboyega, (2020). Implication of workplace sexual harassment of the working women in Nigeria. Sexual. International al Journal of Development and Management Review. 195-211

Chamie, J. (2017). Sexual harassment: At least 2 billion women. Retrieved from htt://www.ipsnews.net/2018/02/sexual-harssment-least- 2 billion-women/amp/world.

Employee Compensation Act. (2010). Wageindicator; understanding labour law and spot oppoturnities. Retrieved 15/10/2021 from mywage.ng

Fitzgerald L. F. (1993). Sexual Harassment, Violence against women in the Workplace, American Psychologist. 48: 1070- 1076.

Fitzgerald, L.F and Gelfand,M.J. (1997). Antecedents and consequences of sexual harassment in Organizations: a test of an integrated model. Applied psycol. 82(4): 578-89) harassment among women working in hospitality workplaces. Public Health 21, 1119 https://doi.org/10.1186/s12889-021-11173-1 
Hartmann HK (1981) "The Unhappy Marriage. Marxism and Feminism: Towards a more Progressive Union", in L. Sergent ed. Women and Revolution, New York: Monthly Review.

International Labour Organization;ILO(2012). Giving globalization a human face. Report 111(part 1B). International Labour Conference, 101th Section, Geneva, para.789.

International Labour Organization;ILO(2020). Report V(1) Ending violence and harassment against women and men in the world of work, ILC, 107/V/1(Geneva).

Kimmel MS (1989) “The Sixties without Metaphor", Society March/April, 77-84.

Ladebo, O. J, (2003). Sexual harassment in academia in Nigeria: How real? Afrincan Journals. 7(2) 50-57

Omonijo, D. J., Uche,O. C., Nwadiafor,K.L and Rotimi, O. A. (2013). A study of sexual harassment in three selected private faith-based universities. Open journal of social science research

Pollert A (1985) "Women, Gender and Wage Labour" in E. Gamarnikow et.al. Gender, Class and Work, Gower Publishing Co. Ltd.

Topa C.G,Morales D.J,and Depolo M.(2008) Perceived sexual harassment at work. Meta analysis and structural model of antecedents/consequences. Span psycho..11:20718(Pudmed)

Worke, M.D., Koricha, Z.B.\& Debelew,G.T.(2021). Perception and experiences of sexual Yusuf, N. (2008) Experience of Sexual Harassment at Work by Female Employees in a Nigerian Work Environment. International NGO Journal Vol. 3 (7), 122-127. 